\title{
The Effect of Remineralisation Treatments on Demineralised Dentine, an In Vitro Study
}

\author{
EmmaMoloney ${ }^{1}$, Srinivas Varanasi ${ }^{1}$, Ian A Meyers ${ }^{1}$, LlewRintoul ${ }^{2}$, Anne L Symons ${ }^{1, *}$ \\ ${ }^{1}$ The University of Queensland, School of Dentistry 200 Turbot Street, Brisbane, Queensland. 4000. Australia \\ ${ }^{2}$ Faculty of Science and Technology, Queensland University of Technology \\ *Corresponding Author:a.symons@uq.edu.au
}

Copyright $($ 2014Horizon Research Publishing. All rights reserved.

\begin{abstract}
This in vitro study evaluated the effect of commercially available remineralising products on demineralised dentine. Demineralised dentine was stored in pooled saliva or treated with Tooth Mousse, Tooth Mousse Plus, Gel-Kam or NeutraFluor 5000, for 7 days at room temperature. Dentine slices were microhardness tested, and assessed using scanning electron microscopy (SEM) and energy dispersive and Raman spectroscopy. Demineralisation decreased dentine microhardness and was increased following storage in saliva. However, Tooth Mousse and NeutraFluor 5000 treatment significantly increased $(p<0.05)$ microhardness. SEM analyses showed that following demineralisation, dentine tubule openings were more clearly defined and treatment with saliva did not alter this surface appearance. Dentine tubules appeared to be occluded following treatment. With the exception of fluoride, few significant differences in elemental content between Tooth Mousse, Tooth Mousse Plus and NeutraFluor5000 were observed. All products significantly increased $(p<0.001)$ fluoride levels compared with control, demineralised and saliva stored specimens. The increase in surface fluoride levels was significantly higher for Gel-Kam and NeutraFluor5000 $(\mathrm{p}<0.001)$. Raman spectrometry indicated that fluoride was being incorporated into apatite crystals following treatment with Tooth Mousse Plus, Neutra Fluor 5000 and Gel-Kam.
\end{abstract}

Keywords Dentine, Demineralisation, Remineralisation

\section{Introduction}

Dentine is a vital, hydrated and complex tissue that forms the largest component of the human tooth (1). Although usually shielded in the oral environment by overlying enamel and periodontal tissues, dentine can become exposed following enamel loss or gingival recession (2). Once exposed, dentine is placed in equilibrium with the surrounding aqueous environment and is susceptible to demineralisation and remineralisation(3).

Dentine remineralisation is a complicated process as it involves the interaction of minerals, collagen and non-collagenous proteins (4). A number of studies support the concept that dentine remineralisation occurs through the growth of residual crystals within the demineralised structures (4-8). The non-collagenous proteins that adhere to the collagen matrix are thought to regulate the process through both inhibitory and acceleratory functions (9, 10).Enhancing dentine remineralisation is important in the treatment of dentinal hypersensitivity, cervical dentine wear and root caries (4).

Dental practitioners prescribe commercially available products in the management of dentine sensitivity symptoms and to enhance remineralisation of teeth in a susceptible oral environment. However, there is limited data available on the potential of these commercial products to manage dentine demineralisation. Most have been developed for the protection of enamel and considering the ultrastructural and compositional differences between enamel and dentine, these products may not exert comparable effects on the two substrates (11).

While the increased porosity of dentine promotes fluoride penetration and the larger surface area offers more nucleation sites (12), relative to enamel, higher fluoride concentrations may be required to enabledentine remineralisation (13-15). Various compounds including sodium fluoride, stannous fluoride, sodium monofluorophosphate and amine fluoride have been employed to deliver fluoride to the oral cavity and while there is an overall consensus that fluoride dentifrices are effective for enhancing the remineralisation of dentine, an optimal concentration or delivery mechanism is yet to be determined (13).In addition, products containing casein phosphopeptide-amorphous calcium phosphate (CPP-ACP) have been shown to promote remineralisation of subsurface enamel lesions (16) but little is documented concerning their effect on the dentine surface.

Therefore, the aim of this in vitro study was to determine the effect of the commercially available products, Tooth Mousse (TM, GC International, Tokyo, Japan), Tooth 
Mousse Plus (TMP, GC International, Tokyo, Japan),NeutraFluor 5000 (NF, Colgate-Palmolive Pty Ltd, Sydney, Australia) and Gel-Kam (GK, Colgate-Palmolive Pty Ltd, Sydney, Australia) on the demineralised dentine surface

\section{Materials and Methods}

\subsection{Dentine Slices}

Dentine slices were prepared from 40 extracted human third molars which had been stored in phosphate buffered saline (PBS) at $4^{\circ} \mathrm{C}$. Mesio-distal dentine slices ( $2 \mathrm{~mm}$ thick) from the buccal aspect of the crown were cut (Fig. 1) using a low speed water-cooled diamond saw (Isomet, Buehler,Lake Bluff, IL, USA). The buccal aspect of each slice was polished with 1200 grit silicon carbide paper and the pulpal aspect coated with a blue, acid-resistant varnish (Atlantic, Rimmel, London). Each slice was divided into three sections to provide a control (Dent-C) for each dentine slice which was stored in distilled water, and the remaining thirds were demineralised and stored in saliva $($ Dent $+S)$ or test solution $($ Dent $+\mathrm{T})$. There were ten samples $(\mathrm{N}=10)$ for each product tested, and each Dent+Tdentine section had a matched Dent-C and Dent $+\mathrm{S}$ section. Approval for the research project using extracted human teeth, was granted by The University of Queensland, School of Dentistry Research Committee.

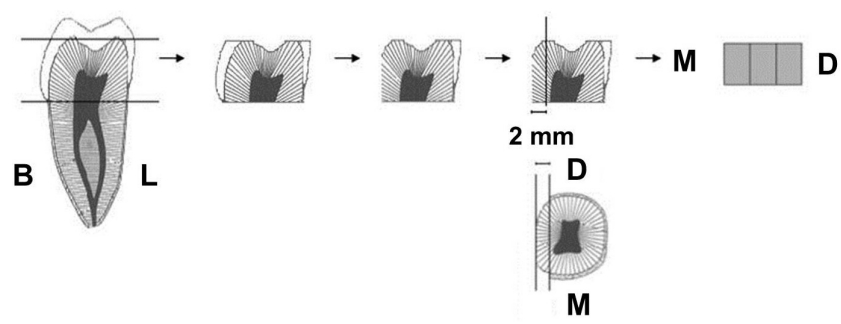

Figure 1. Dentine slices, $2 \mathrm{~mm}$ thick, were prepared from the buccal (B) aspect of the tooth crown. Lingual (L), mesial (M), distal (D).

\subsection{Demineralisation}

Dentine was demineralised using the technique described by Smith et al., (17). Briefly, dentine slices were treated with $5 \mathrm{~mL}$ of an acetic buffer system at room temperature. The buffer system consisted of $50 \mathrm{mM}$ acetate buffer solution at a $\mathrm{pH} 4.5$ containing $2.2 \mathrm{mM}$ each of potassium dihydrogen orthophosphate $\left(\mathrm{KH}_{2} \mathrm{PO}_{4}\right)$ and calcium chloride $\left(\mathrm{CaCl}_{2}\right)$ and $0.5 \mathrm{ppm}$ fluoride in the form of sodium fluoride $(\mathrm{NaF})$. Following three days of demineralisation, specimens were washed with distilled water for 30 minutes.

\subsection{Saliva Collection}

Unstimulated saliva was pooled from three individuals. Samples were obtained daily at the same time to minimise diurnal variations in saliva. In the two hours prior to collection, participants were instructed to avoid eating, drinking and tooth brushing. Participants were seated in a quiet area. Participants sat with their head bent forward, to allow saliva to pool in the mouth and instructed to expectorate unstimulated saliva into $14 \mathrm{~mL}$ plastic tubes for 5 $\min (18)$.

\subsection{Storage Solutions}

Dentine sections were stored in $2 \mathrm{~mL}$ of solution for seven days at room temperature and washed in PBS when solutions were changed 24-hourly. Dent-C sections were stored in distilled water, Dent $+\mathrm{S}$ sections in pooled saliva and Dent $+\mathrm{T}$ sections in pooled saliva with $0.5 \mathrm{~mL}$ of the test product. Products tested are shown in Table 1.

Table 1. Products tested

\begin{tabular}{|ccc|}
\hline Product & Manufacturer & Active Ingredients \\
\hline Tooth Mousse & GC International & $10 \% \mathrm{CPP}-\mathrm{ACP}$ \\
\hline Tooth Mousse Plus & GC International & $10 \% \mathrm{CPP}-\mathrm{ACP}, 0.2 \% \mathrm{NaF}$ \\
\hline NeutraFluor 5000 & Colgate-Palmolive & $1.1 \% \mathrm{NaF}$ \\
\hline Gel-Kam & Colgate-Palmolive & $0.4 \% \mathrm{SnF}_{2}$ \\
\hline
\end{tabular}

\subsection{Microhardness Testing}

Using a paralleling machine (Leitz, Wetzlar, Germany) dentine specimens were mounted on glass slides with wax and the Vickers hardness determined using a mini-load hardness tester (Leitz, Wetzlar, Germany). A Vickers diamond pyramid indenter was pushed into the dentine using an indentation load of $300 \mathrm{~g}$ with a $15 \mathrm{~s}$ dwell time. Each slab was subjected to two indentations which were separated by at least $500 \mu \mathrm{m}$. The indentation diagonal was measured by optical microscopy. For each sample, the average diagonal length was used to calculate the Vickers hardness (HV, $\mathrm{kg} / \mathrm{mm}^{2}$ ) according the following formula, where $\mathrm{P}$ is load ( $\mathrm{g}$ ) and $\mathrm{d}$ is the average length of the diagonal $(\mu \mathrm{m})$;

$$
H V=\frac{1854 \times P}{d^{2}}
$$

\subsection{Scanning Electron Microscopy (SEM) Analysis}

Slices were washed in distilled water and the surface morphology examined using aSEM (JEOL 6440LA, Tokyo, Japan), and surface composition determined using Energy Dispersive Spectroscopy (EDS). EDS was conducted in the low vacuum mode, at a working distance of $10 \mathrm{~mm}$, accelerating voltage of $15 \mathrm{kV}, 55 \mathrm{~mm}$ spot size and $15 \mathrm{~Pa}$ pressure, using the backscattered electron detector. On each specimen, three spot measurements were carried out in the intertubulardentine at a spot size of 0.3-0.4 $\mu \mathrm{m}$. Images were taken at 4000x magnification and captured electronically with the JEOL Analytical SEM software.

\section{Raman Spectrometry}


Each specimen treated with a fluoride containing product was examined using FT-Raman and micro-Raman spectrometry. Briefly, FT-Raman spectra were measured with a Perkin-Elmer System 2000 NIR FT-Raman spectrometer (Waltham, Massachusetts, USA), equipped with a diode pumped Nd-YAG laser (1064 $\mathrm{nm})$ as an excitation source and an InGaAs photoelectric detector operating at room temperature. Spectra were recorded over a range of $3800-200 \mathrm{~cm}^{-1}$ at $8 \mathrm{~cm}^{-1}$ resolution using a laser power of $320 \mathrm{~mW}$ at a diameter of $300 \mu \mathrm{m}$ on the specimen. Micro-Raman measurements were carried out on a Renishaw System 1000 Raman microscope using a HeNe laser giving $10 \mathrm{~mW}$ of $633 \mathrm{~nm}$ radiation at a diameter of $1.0 \mu \mathrm{m}$ on the specimen. Micro-Raman spectra were recorded in the range $1875-875 \mathrm{~cm}^{-1}$ with a resolution of better than $4 \mathrm{~cm}^{-1}$ by accumulating $4 \times 60 \mathrm{~s}$ scans. Calibration was performed by referencing the spectrometer to the $520.5 \mathrm{~cm}^{-1}$ band of a silicon wafer.

\section{Data Analysis}

Data were analysed using one-way analysis of variance (ANOVA) and the Bonferroni Multiple Comparison test (Graph Pad Instat 3, San Diego, California, USA).

\section{Results}

\subsection{Dentine Microhardness}

Demineralisation significantly $(\mathrm{p}<0.001)$ decreased the microhardness of the dentine surface and storage in saliva significantly $(p<0.01)$ increased the microhardness of demineralised dentine (Fig.2). There was no significant difference between saliva-stored specimens and those stored in saliva to which a treatment product was added. Within the product treatment groups, microhardness was higher for the TM and GK, microhardness for the TMP group was significantly $(\mathrm{p}<0.05)$ less than that recorded for GK, and the microhardness for NF was significantly $(p<0.001)$ less that observed for TM and GK.

\subsection{SEM}

A smear layer was present on the surface of controls and tubules were identified (Fig.3a). Similar observations were noted for demineralised specimens, but tubule openings were more clearly defined (Fig.3b) and storage in saliva did not alter the surface appearance (Fig.3c). A smear layer was present on all dentine surfaces and variation in surface morphology was noted following treatment (Figs. 3d-g). Tubule morphology was observed in sections following treatment with Tooth Mousse products, indicating the surface layer deposit remained thin. A fine granular deposit was noted for the NF-treated specimens and a thick globular deposit was observed for GK-treated specimens.

\subsection{EDS}

Results of the EDS spot analysis are summarised in Table 2. The EDS x-ray spectra of the intertubular dentine surface demonstrated prominent calcium and phosphorous peaks, with lower peaks for fluoride. Statistical comparison of the elemental content revealed few differences between control, demineralised and saliva-treated dentine. A significant difference between control and treatment groups was evident for fluoride $(p<0.001)$ levels. Fluoride levels were significantly higher for NF and GK compared with the Tooth Mousse products $(\mathrm{p}<0.001)$.

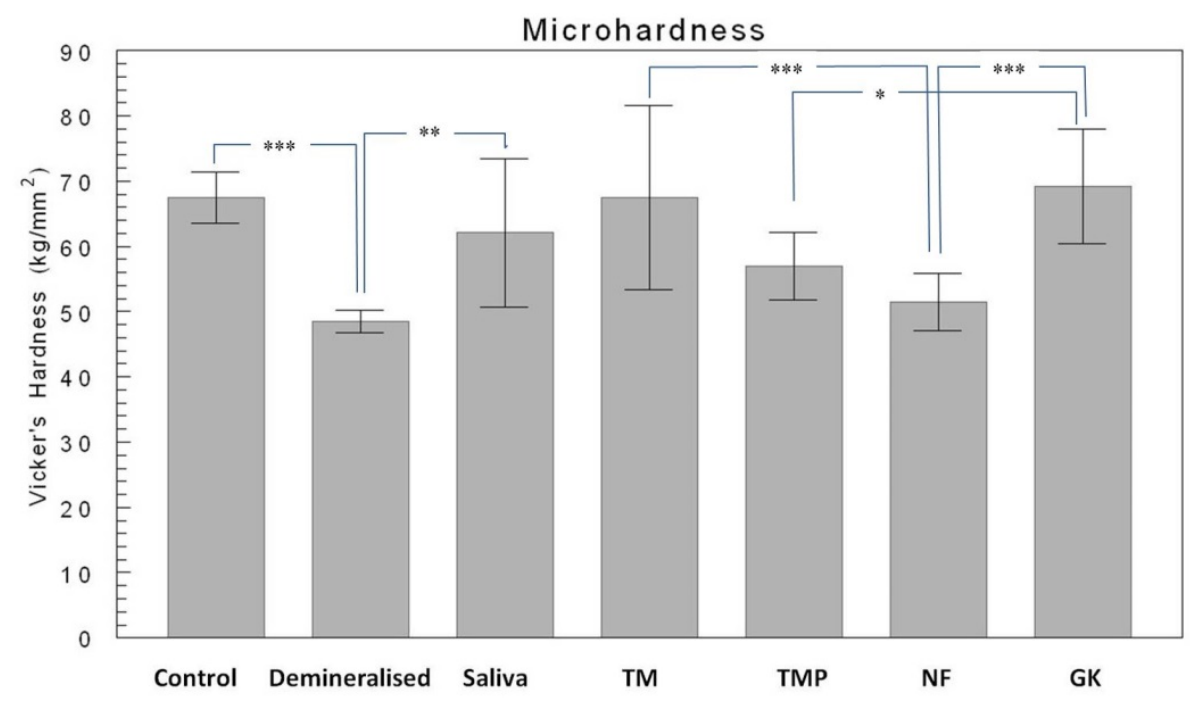

Figure 2. Mean (SD) Vickers hardness $\left(\mathrm{kg} / \mathrm{mm}^{2}\right)$ of the dentine surface $(\mathrm{N}=10)$ for each group. ${ }^{*} \mathrm{p}<0.05 ; * * \mathrm{p}<0.01 ; * * * \mathrm{p}<0.001$. 

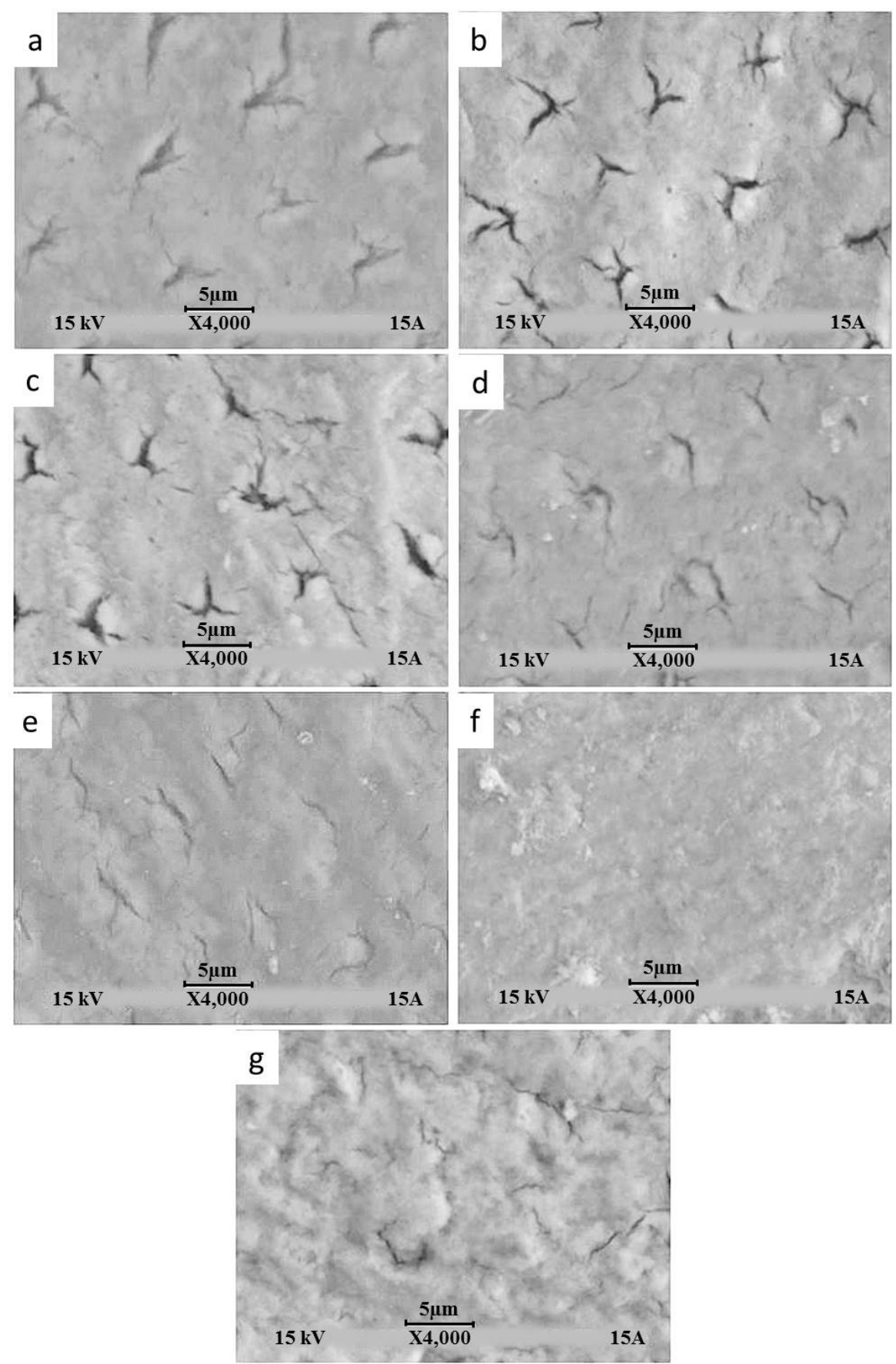

Figure 3. SEM images of the dentine surface for (a) control, (b) demineralised, (c) saliva, (d) TM, (e) TMP, (f) NF and (g) GK specimens. Bar represents $5 \mu \mathrm{m}, \mathrm{N}=10$.

Table 2. EDS analysis showing mean (SD)per cent element content $(\mathrm{N}=10)$. Fluoride levels were significantly higher $\left({ }^{\#} \mathrm{p}<0.001\right)$ for the treatment groups compared with control, demineralised and saliva-treated groups. Fluoride levels were significantly higher $(* * * \mathrm{p}<0.001)$ for NF and GK compared with TM and TMP.

\begin{tabular}{|cccccccc|}
\hline \multirow{2}{*}{ Element } & Control & Demineralized & Saliva & TM & TMP & NF & GK \\
\hline \multirow{2}{*}{ Calcium } & 36.37 & 39.02 & 40.51 & 39.80 & 39.78 & 40.33 & 32.52 \\
& $(2.02)$ & $(2.51)$ & $(2.36)$ & $(1.67)$ & $(0.94)$ & $(2.78)$ & $(1.30)$ \\
\hline \multirow{2}{*}{ Phosphate } & 18.45 & 19.20 & 19.45 & 19.06 & 19.29 & 19.65 & 17.67 \\
& $(0.80)$ & $(0.52)$ & $(0.68)$ & $(0.68)$ & $(0.87)$ & $(1.04)$ & $(1.04)$ \\
\hline \multirow{2}{*}{ Fluoride } & 0.11 & 0.11 & 0.15 & 0.39 & 0.7 & 1.81 & 1.39 \\
& $(0.08)$ & $(0.09)$ & $(0.08)$ & $(0.25)^{\#}$ & $(0.02)^{\#}$ & $(0.41)^{\#, * * * *}$ & $(0.37)^{\#, * * * *}$ \\
\hline
\end{tabular}




\subsection{Raman Spectroscopy}

The FT-Raman spectrum of the dentine tubule wall of a control sample is shown in Figure 4. The spectrum is dominated by bands attributed to the phosphate moiety and collagen of the dentine. Bands of the phosphate $\left(\mathrm{PO}_{4}{ }^{-3}\right)$ incorporated within the hydroxyapatite crystals were observed near $959 \mathrm{~cm}^{-1}$ (and at 582 and $428 \mathrm{~cm}^{-1}$ ), corresponding to the stretching and deforming vibration modes of oxygen to phosphorous bonds. Collagen bands observed are the amide A and amide I and III bands of the peptide linkage at 3335,1668 and $1250 \mathrm{~cm}^{-1}$, respectively, and the $\mathrm{CH}$ stretch and $\mathrm{CH}$ deformation modes at 2938 and $1449 \mathrm{~cm}^{-1}$, respectively. The carbonate symmetric stretching vibration is also observed at $1070 \mathrm{~cm}^{-1}$.

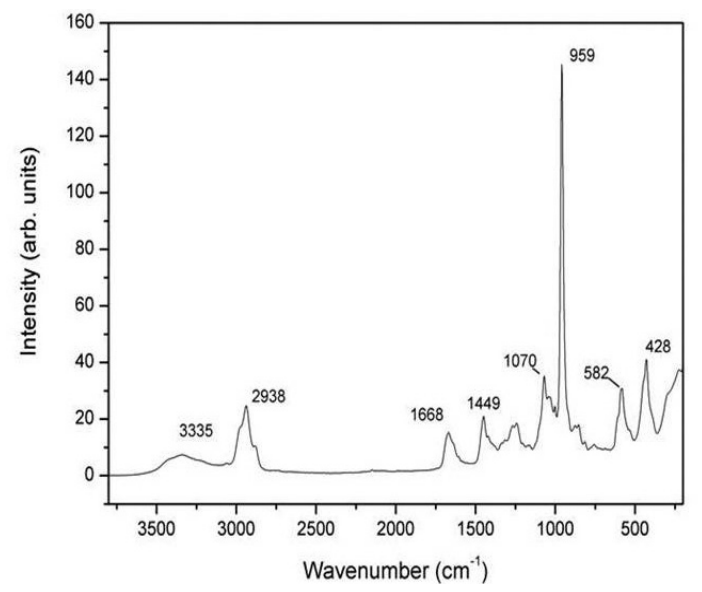

Figure 4. FT-Raman spectrum of the dentine tubule wall for a control specimen.

The wavenumber position of sharp dominating peaks, such as the $\mathrm{PO}_{4}{ }^{-3}$ stretch are more precisely determined than band areas and can be sensitive probes of the local chemical environment of the vibrating moiety. Small but significant differences in the peak positions were observed in both the FT-Raman and micro-Raman data (Table 3), between the control, demineralised and saliva samples and theTMP, NFand GK samples $(\mathrm{p}<0.001)$. The $\mathrm{PO}_{4}{ }^{-3}$ peak positions were within $+/-0.2$ of $959.5 \mathrm{~cm}^{-1}$ for the former group and within $960.6+/-0.6 \mathrm{~cm}^{-1}$ for the latter, with NF showing the largest effect.

Table 3. Micro-Raman peak positions, wavenumber $\left(\mathrm{cm}^{-1}\right)$. A significant change $(* * * p<0.001)$ in peak position for dentine treated with fluoride products was observed compared with the control, demineralised and saliva-treated dentine.

\begin{tabular}{|cc|}
\hline Group & Peak position, $\mathbf{c m}^{-\mathbf{1}}$ \\
\hline Control & 959.45 \\
\hline Demineralised & 959.45 \\
\hline Saliva & 959.60 \\
\hline TMP & $960.55^{* * *}$ \\
\hline NF & $961.19^{* * *}$ \\
\hline GK & $960.02^{* * *}$ \\
\hline
\end{tabular}

\section{Discussion}

This in vitro study showed that the commercially available remineralising products tested, were capable of inducing changes in dentine surface topography and composition following a seven day storage period. Greater changes in these parameters were observed following treatment with fluoride containing products. The demineralisation protocol lowered the microhardness of the dentine surface and following storage in saliva, surface microhardness was restored to a value similar to that observed prior to demineralisation. Variation in surface microhardness was observed between the treatment groups. Microhardness results for TMP were significantly $(\mathrm{p}<0.05)$ lower compared with results for GK, and NF microhardness results were significantly $(\mathrm{p}<0.001)$ lower than those for TM and GK.However, long-term discrimination between the different products was not possible due to the short demineralisation and storage periods used in this study.

Microhardnesswas used as an indirect method fordetermining changes in mineral content as microhardness of dentine may reflect a reduction in mineral content (19-21). A demineralisation period of three days was selected for this study as a longer period may deplete the collagen matrix of mineral and thus inhibit remineralisation $(22,23)$. The ability of pooled saliva to restore the microhardness of demineralised dentine was observed in the current in vitro study. This may be due to the calcium and phosphate saturation and buffering capacity characteristics of saliva that enhance remineralisation(24). The addition of TMP or $\mathrm{NF}$ to pooled saliva appeared to delay recovery of microhardness for these groups, although the microhardness of the treatment groups was not statistically different from the saliva group for the time interval examined. A longer experimental period may result in higher microhardness for the treatment groups. However, collected saliva may undergo changes which alter the chemical composition and properties and thus the in vitrouse of saliva may not reflect in vivo behaviour (25).

Variation in dentine surface microhardness was observed between the treatment groups. TMand GK showed the greater microhardness, suggesting a greater mineral gain than that recorded for TMP and NF. Similarly, TM and GK have been shown to have the capacity to remineralisedentine, in vitro (26-28). The lack of change in dentine microhardness followingTMP and NFtreatment is difficult to explain, as sodium fluoride dentifrices have been shown to remineralisecarious dentine $(29,30)$. However, these results may be related to the application protocol and test interval $(31,32)$.

The non-homogeneous nature of dentine impacts upon microhardness measurements when an indentation system is used. Different microhardness values have been reported for peritubular and intertubulardentine(19). Due to the size of the indentor relative to dentine microstructure, hardness values are dependent upon which structure theindentor contacts $(19,33)$. To overcome this, each dentine slab was 
subjected to two indentations and the mean microhardness for each group used in the analysis. However, large standard deviations values for the saliva, TM and GK groups were observed.

Despite the decrease in microhardness, SEM showed the dentine surface morphology was not markedly changed using the demineralisation protocol in the current study. The presence of fluoride in demineralising solutions is known to allow subsurface demineralization $(12,17,34)$ and protects the surface from the acetate buffer (17). This lack of change in the SEM appearance of the surface following storage in salivahas been reported previously (35).

The globular deposit observed on surfaces treated with GK is consistent with other SEM studies (35-39). This globular layer is reported to be a mixture of low solubility complexes of tin including hydroxide, oxygen, phosphate and fluoride (36) and is reported to alleviate dentine hypersensitivity $(36,40,41)$.The granular surface deposits on the NF specimens have also been reported and are believed to be composed of calcium fluoride $(42,43)$.

Due to the uneven tissue density, EDS does not provide absolute measurements when dentine is analysed, but measurements on a relative scale are of value (44). Consistencies and differences of the surface composition between the groups could be assessed and correlated. However, since EDS only measures to a depth of $2-3 \mu \mathrm{m}$, elemental differences may be due to the surface precipitate and not changes in the inorganic component of dentine in response to changes in mineralisation. This could account for the results observed for GK-treated dentine and the differences in fluoride levels observed between the treatment groups. As previously reported (45), little difference was observed in the surface composition of the control, demineralised and saliva treated dentine. A tin-rich deposit may form following treatment with GK, as high levels of surface tin in dentine treated with anhydrous stannous fluoride have been reported (36). Consequently, these high tin levels would alter the relative percent of other elements on the dentine surface.

EDS fluoride measurements tended to reflect the fluoride concentration of the test product. Dentine samples treated with NF demonstrated the highest fluoride level, suggesting the presence of a calcium fluoride precipitate $(35,43)$ and the high fluoride level in GK-treated dentine indicated the presence of fluoride ligands known to complex with stannous ion in solution (36). Lower levels of fluoride were detected in TMP specimens and while this may be due to the lack of surface precipitate, the fluoride level was elevated compared with control, demineralised and saliva-stored specimens.

The FT-Raman signal arises from a near cylindrical sampling volume defined by the diameter of the laser focal spot, in this case $300 \mu \mathrm{m}$. The NIR laser may penetrate up to $1 \mathrm{~mm}$ deep or greater in solid, visibly opaque samples, such as dentine. In contrast, micro-Raman measurements are obtained from a very tight focal spot of the order of $1 \mu \mathrm{m}$ with a depth of field of $10 \mu \mathrm{m}$ or less. Thus micro-Raman measurements are near surface measurements whereas FT-Raman spectra are more representative of the bulk. Micro-Raman spectra of the tubule walls were similar to the FT-Raman spectrum, but there were differences in the relative intensities across the spectral region, as expected owing to the different excitation wavelengths and differences in the spectrometer throughputs. While not directly comparable, a semi-quantitative measure of the relative proportion of organic to inorganic material in teeth may be obtained from spectra from either instrument by taking a ratio of the area of the $\mathrm{PO}_{4}$ symmetric stretching vibration to that of the amide I band.

The peak position of the phosphate symmetric stretch is a measure of the crystal environment of the phosphate. In pure fluorapatite (FAP) the peak position is found at $964.2 \mathrm{~cm}^{-1}$, compared to $962.8 \mathrm{~cm}^{-1}$ for hydroxyapatite (HAP)(46). This shift to higher wave number is due to either the effect fluoride has directly on the phosphate ion and/or the small different unit cell volume in FAP compared to HAP. Thus, the observed shifts noted after treatment indicate fluoride had replaced the hydroxyl ion in the crystal lattice. This effect was strongest for NF and TMP.

\section{Conclusion}

The commercially available products tested in this study altered the surface morphology and composition of demineralised dentine following seven days treatment in vitro. The products did not appear to increase surface microhardness during the experimental period. Changes observed in element content and surface morphology are most likely due to deposition of material onto the dentine surface as opposed to within the dentine structure. However, Raman spectrometry indicated that fluoride was being incorporated into apatite crystals within the dentine following treatment with NF, TMP and GK. Given the limitations of this in vitro model, further studies are required to evaluate the long term effectiveness of these products within the oral environment.

\section{Acknowledgements}

The project was supported by a grant from the Australian Dental Research Foundation

\section{REFERENCES}

[1] G. W. Marshall. Dentin: microstructure and characterization, Quintessence International Vol. 24, No. 9, 606-617, 1993.

[2] M. Addy, N. Pearce. Etiologic, predisposing and environmental factors in dentin hypersensitivity, Archives of Oral Biology, Vol. 39, S33-S38, 1994.

[3] B. Nyvad, J. M. tenCate, O. Fejerskov. Arrest of root surface 
caries in situ, Journal of Dental Research, Vol. 76, No. 12, 1845-1853, 1997.

[4] K. Kawasaki, J. Ruben, I. Stokroos, O. Takagi, J. Arenda. The remineralization of EDTA-treated human dentine, Caries Research, Vol. 33, No. 4, 275-280, 1999.

[5] B. Klont, J. M. ten Cate. Remineralization of bovine incisor root lesions in vitro. The role of the collagenous matrix, Caries Research, Vol. 25, No. 1, 39-45, 1991.

[6] G. Daculsi, B. Kerebel, M. T. Lecabellec, L. M. Kerebel. Qualitative and quantitative data on arrested caries in dentin, Caries Research, Vol. 13, No. 4, 190-202, 1979.

[7] Y. P. Qi, N. Li, L. N. Niu, C. M. Primus, J. Q. Ling, D. H. Pashley, F. R. Tay. Remineralization of artificial dentinal caries lesions by biomimetically modified mineral trioxide aggregate, Acta Biomaterialia, Vol. 8, No. 2, 836-842, 2012.

[8] Z. Xu, K. G. Neoh, C. C. Lin, A. Kishen. Biomimetic deposition of calcium phosphate minerals on the surface of partially demineralized dentine modified with phosphorylated chitosan, Journal of Biomedical Materials Research Part B-Applied Biomaterials, Vol. 98B, No. 1, $150-159,2011$

[9] A. Linde. Dentin matrix proteins: composition and possible functions in calcification, Anatomical Record, Vol. 224, No. 2, 154-166, 1989

[10] A. Lussi, A. Linde. Mineral induction in vivo by dentin proteins, Caries Research, Vol. 27, No. 4, 241-248, 1993.

[11] L. Hong, R. L. Ettinger, C. A. Watkins, J. S. Wefel. In vitro evaluation of fluoride varnish on overdenture abutments, Journal of Prosthetic Dentistry, Vol. 89, No. 1, 28-36, 2003.

[12] J. M. ten Cate, J. J. M. Damen, M. J. Buijs. Inhibition of dentin demineralization by fluoride in vitro, Caries Research, Vol. 32, No. 2, 141-147, 1998.

[13] J. D. Featherstone. Fluoride, remineralization and root caries, American Journal of Dentistry, Vol. 7, No. 5, 271-274, 1994.

[14] I. Diamanti, H. Koletsi-Kounari, E. Mamai-Homata, G. Vougiouklakis. Effect of fluoride and of calcium sodium phosphosilicate toothpastes on pre-softened dentin demineralization and remineralization in vitro, Journal of Dentistry, Vol. 38, No. 8, 671-677, 2010.

[15] I. Diamanti, H. Koletsi-Kounari, E. Mamai-Homata, G. Vougiouklakis. In vitro evaluation of fluoride and calcium sodium phosphosilicate toothpastes, on root dentine caries lesions, Journal of Dentistry, Vol. 39, No. 9, 619-628, 2011.

[16] E. C. Reynolds. Remineralization of enamel subsurface lesions by casein phosphopeptide-stabilized calcium phosphate solutions, Journal of Dental Research, Vol. 76, No. 9, 1587-1595, 1997.

[17] P. W. Smith, K. P. Preston, S. M. Higham. Development of an in situ root caries model. A. In vitro investigations, Journal of Dentistry, Vol. 33, No. 3, 253-267, 2005.

[18] M. F. Z. Scelza, D. D. Silva, N. K. Ahiadzro, L. E. da Silva, P. Scelza. The influence of medication on salivary flow of the elderly: preliminary study, Gerodontology, Vol. 27, No., $278-282,2010$

[19] L. Angker, C. Nockolds, M. V. Swain, N. Kilpatrick. Correlating the mechanical properties to the mineral content of carious dentine - a comparative study using an ultra-micro indentation system (UMIS) and SEM-BSE signals, Archives of Oral Biology, Vol. 49, No. 5, 369-378, 2004.

[20] J. Arends, J. J. Tenbosch. Demineralization and remineralization evaluation techniques., Journal of Dental Research, Vol. 71, No., 924-928, 1992.

[21] J. J. Ten Bosch, B. Angmar-Mansson. A review of quantitative methods for studies of mineral content of intraoral incipient caries lesions., Journal of Dental Research, Vol. 70, No. 1, 2-14, 1991.

[22] J. R. Heilman, T. H. Jordan, R. Warwick, J. S. Wefel. Remineralization of root surfaces demineralized in solutions of differing fluoride levels, Caries Research, Vol. 31, No. 6, 423-428, 1997.

[23] B. H. Clarkson, D. L. Hall, J. R. Heilman, J. S. Wefel. Effect of proteolytic enzymes on caries lesion formation in vitro, Journal of Oral Pathology \& Medicine, Vol. 15, No. 8, 423-429, 1986

[24] I. D. Mandel. The functions of saliva., Journal of Dental Research, Vol. 66, No., 623-627, 1987.

[25] A. F. Hall, C. A. Buchanan, D. T. Millett, S. L. Creanor, R. Strang, R. H. Foye. The effect of saliva on enamel and dentine erosion, Journal of Dentistry, Vol. 27, No. 5, 333-339, 1999.

[26] C. Rahiotis, G. Vougiouklakis. Effect of a CPP-ACP agent on the demineralization and remineralization of dentine in vitro, Journal of Dentistry, Vol. 35, No. 8, 695-698, 2007.

[27] S. H. Y. Wei, W. C. Forbes. Effect of particle size on reactions of powdered sound human enamel and dentin with stannous fluoride solution, Archives of Oral Biology, Vol. 17, No. 10, 1467-1472, 1972

[28] S. H. Y. Wei, J. C. Kaqueler, M. Massler. Remineralisation of carious dentin, Journal of Dental Research, Vol. 47, No. 3, $381-391,1968$.

[29] R. J. Sullivan, R. Fletcher, R. Bachiman, B. Penugonda, R. Z. LeGeros. Intra-oral comparison and evaluation of the ability of fluoride dentrifices to promote the remineralization of caries-like lesions in dentin and enamel, Journal of Clinical Dentistry, Vol. 6, No. 2, 135-138, 1995.

[30] A. Baysan, E. Lynch, R. Ellwood, R. Davies, L. Petersson, P. Borsboom. Reversal of primary root caries using dentifrices containing 5,000 and 1,100 ppm fluoride, Caries Research, Vol. 35, No. 1, 41-46, 2001.

[31] Y. Mukai, M. D. Lagerweij, J. M. ten Cate. Effect of a solution with high fluoride concentration on remineralization of shallow and deep root surface caries in vitro, Caries Research, Vol. 35, No. 5, 317-324, 2001.

[32] R. L. Ettinger, R. J. Olson, J. S. Wefel, C. Asmussen. In vitro evaluation of topical fluorides for overdenture abutments, Journal of Prosthetic Dentistry, Vol. 78, No. 3, 309-314, 1997.

[33] J. H. Kinney, M. Balooch, S. J. Marshall, G. W. Marshall, T. P. Weihs. Hardness and Young's modulus of human peritubular and intertubular dentine, Archives of Oral Biology, Vol. 41, No. 1, 9-13, 1996.

[34] J. M. Tencate, M. J. Buijs, J. J. M. Damen. pH-Cycling of enamel and dentin lesions in the presence of low 
concentrations of fluoride, European Journal of Oral Sciences, Vol. 103, No. 6, 362-367, 1995.

[35] M. Addy, P. Mostafa. Dentin hypersensitivity.1. Effects produced by the uptake in vitro of metal ions, fluoride and fromaldehyde onto dentin, Journal of Oral Rehabilitation, Vol. 15, No. 6, 575-585, 1988.

[36] T. T. Miller S, Heu R, Stranick M, Bouchard D, Gaffar A. Recent advances in stannous flouride technology: antibacterial efficacy and mechanism of action towards hypersensitivity, International Dental Journal, Vol. 44, No. 1, 83-98, 1994.

[37] J. E. Ellingsen, G. Rolla. Treatment of dentin with stannous fluoride - SEM and electron microprobe study, Scandinavian Journal of Dental Research, Vol. 95, No. 4, 281-286, 1987.

[38] M. Davies, E. M. Paice, S. B. Jones, S. Leary, A. R. Curtis, N. X. West. Efficacy of desensitizing dentifrices to occlude dentinal tubules, European Journal of Oral Sciences, Vol. 119, No. 6, 497-503, 2011.

[39] T. Y. Ning, X. H. Xu, L. F. Zhu, X. P. Zhu, C. H. Chu, L. K. Liu, Q. L. Li. Biomimetic mineralization of dentin induced by agarose gel loaded with calcium phosphate, Journal of Biomedical Materials Research Part B-Applied Biomaterials, Vol. 100B, No. 1, 138-144, 2012.

[40] D. M. Thrash WJ, Jones DL. The effect of stannous fluoride on dentinal sensitivity, International Dental Journal, Vol. 44,
No. 1, 107-118, 1994.

[41] M. A. Blong, B. Volding, W. J. Thrash, D. L. Jones. Effects of a gel containing 0.4 percent stannous fluoride on dentinal hypersensitivity, Dental Hygiene, Vol. 59, No. 11, 489-492, 1985.

[42] M. Addy, P. Mostafa. Dentin hypersensitivity 1. Effects produced by the uptake in vitro of metal ions, fluoride and formaldehyde onto dentin, Journal of Oral Rehabilitation, Vol. 15, No. 6, 575-585, 1988.

[43] M. Tal, M. Oron, I. Gedalia, J. Ehrlich. X-Ray diffraction and scanning electron microscope investigations of fluoride-treated dentin in man, Archives of Oral Biology, Vol. 21, No. 5, 285-290, 1976.

[44] E. Hals, A. B. Tveit, B. Totdal. X-Rray microanalysis of dentin. A review, Scanning Microscopy, Vol. 2, No. 1, 357-369, 1988.

[45] W. H. Arnold, S. Konopka, P. Gaengler. Qualitative and quantitative assessment of intratubular dentin formation in human natural carious lesions, Calcified Tissue International, Vol. 69, No. 5, 268-273, 2001.

[46] J. W. Xu, D. F. R. Gilson, I. S. Butler, I. Stangel. Effect of high external pressures on the vibrational spectra of biomedical materials: Calcium hydroxyapatite and calcium fluoroapatite, Journal of Biomedical Materials Research, Vol. 30, No. 2, 239-244, 1996. 